\title{
EN BUSCA DEL ESPECTÁCULO PREHISPÁNICO NAHUA EN FIESTAS Y REPRESENTACIONES TEATRALES COLONIALES ${ }^{1}$
}

ABSTRACT In Search for Pre-Hispanic Performance in Colonial Festivals and Theatrical Representations

The aim of this paper is to present civil and religious festivals, as well as theatrical representations, performed in the sixteenth-century New Spain, as examples of the convergence of elements introduced by the Spaniards and those already existing in the indigenous culture. Taking as a starting point a schematic presentation of such activities as dances, song performances, jugglers' shows, mock battles and evangelization theater, our objective is to signal that due to the presence of certain pre-Hispanic patrons for all these endeavors it is risky to qualify the indigenous contribution as superficial and limit it to the audiovisual elements. The issue is much more complex and the adoption of the native perspective, apart from that of the Spaniards, may reveal the profundity of the convergence of features proper to the Old and New World and help to unveil the perception and reception of the sixteenth-century Mexican performances by its native inhabitants.

Keywords: Nahuas, performance, festival, New Spain, theatre

Palabras clave: nahuas, espectáculo, festival, Nueva España, teatro

\footnotetext{
El presente artículo forma parte del proyecto "Los espectáculos prehispánicos de los nahuas: formas teatrales indígenas a través de las fuentes escritas y los manuscritos pictográficos del México Central” financiado por el Centro Nacional de la Ciencia (NCN) en Polonia a través de la decisión No. DEC-2011/01/N/ HS3/02188. Asimismo, en el trabajo se han utilizado los materiales obtenidos gracias a la colaboración en el marco del proyecto FOCUS financiado por la Fundación para la Ciencia Polaca (FNP).
} 


\section{INTRODUCCIÓN}

Cuando fray Alonso Ponce se acercaba al pueblo de Patamba de la guardianía de Tarécuato en noviembre de 1586, le salieron al encuentro unos veinte indígenas armados para darle la bienvenida y para advertirle de los posibles ataques de los chichimecas, por lo cual ellos mismos, por cuestiones de seguridad, le iban a acompañar en el último

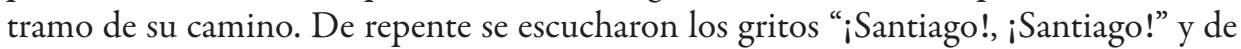
los arbustos circundantes saltaron otros indígenas en trajes chichimecas y "comenzaron a hacer monerías y ademanes". Así el padre comisario, inconscientemente, se convirtió en uno de los protagonistas y al mismo tiempo en el espectador principal de una representación de las llamadas danzas chichimecas².

Este es solo uno de los ejemplos de la gran variedad de fiestas presentes en la vida de la sociedad novohispana en el siglo XVI. Fray Juan de Torquemada las dividió en dos grupos: las denominadas por él fiestas solemnes que describe las que en este estado de gracia son instituidas por la Iglesia, y las repentinas: son las que los emperadores, reyes y señores mandan celebrar, en las repúblicas, por algunas particulares razones y causas; conviene a saber, por alguna victoria militar, que ha tenido de sus enemigos o por haberse casado o por haberle nacido algún hijo heredero de su corona, cuyo nacimiento manda solemnizar $y$ festejar en sus señorios y reinos ${ }^{3}$.

Estas últimas continuaban la tradición de actividades festivas europeas medievales y renacentistas ${ }^{4} \mathrm{y}$, al igual que las fiestas relacionadas con el año litúrgico cristiano, contaban con la presencia de la población indígena. Su función principal en las fiestas civiles fue actuar como "vasallos perfectos" y así confirmar en nuevo concepto de gobierno colonial y la jerarquía social y étnica de la capital que reforzaban el control español ${ }^{5}$. En las religiosas, por otra parte, los indígenas parecen haber sido simplemente su razón de ser, el objeto de la tarea evangelizadora emprendida a gran escala por los misioneros.

Esta definición del papel de los indígenas en las ceremonias coloniales refleja sobre todo el punto de vista de los españoles. En el presente trabajo vamos a acercarnos al rico mundo de espectáculos novohispanos del siglo XVI con el fin de señalar la presencia del elemento indígena en la realización de las festividades civiles y religiosas e intentando adoptar también su óptica. Nuestro estudio no pretende ser exhaustivo: su objetivo es más bien sintetizar distintas opiniones acerca de la influencia nativa en las fiestas y re-

2 Antonio de Ciudad Real, Tratado curioso y docto de las grandezas de la Nueva España. Relación breve y verdadera de lagunas cosas de las muchas que sucedieron al padre fray Alonso Ponce en las provincias de la Nueva España siendo comisario general de aquellas partes, ed. J. García Quintana, V.M. Castillo Farreras, Vol. 1, México 1993, p. 82-83.

3 J. de Torquemada, Monarquía indiana, introd. M. León Portilla, Vol. 3, México 1986, p. 358 (Biblioteca Porrúa, 43).

4 O. Rivera, 'Fiestas por los Austrias en la Ciudad de México, siglo XVI', Revista Destiempos. Dossier Virreinatos, Año 3, Núm. 14 (2008), p. 251.

5 L.A. Curcio-Nagy, The Great Festivals of Colonial Mexico City. Performing Power and Identity, Albuquerque 2004, p. 42 (Diálogos). La traducción del inglés es nuestra. 
presentaciones coloniales e indicar lo complejo del asunto, por lo que muchas veces es imposible, tomando en cuenta los documentos y las fuentes que están a nuestro alcance, decidir el grado de la aportación indígena y de la imposición por parte de los misioneros españoles en las representaciones y ceremonias coloniales.

\section{LOS BAILES Y CANTOS INDÍGENAS}

En la época prehispánica en todas las ceremonias religiosas aparecían los danzantes, quienes con su coreografía, los cantos y el atavío participaban en la acción ritual ${ }^{6}$. Motolinía en sus Memoriales agrupa estos bailes en dos tipos: el vno es maceuializtli y el otro netotiliztli. Este postrero quiere dezir propiamente "bayle de rregocijo" con que se solazan y toman plazer los yndios en sus propias fiestas, ansí como los señores y principales en sus casas y en sus casamientos ${ }^{7}$. Aunque parece que el franciscano quiso marcar la distincción entre los bailes sagrados y los profanos, resulta que hacer tal separación no es del todo fácil, sobre todo si tomamos en cosideración el carácter de los testimonios de los que disponemos: las descripciones de los bailes aparecen en la mayoría de los casos en el contexto ritual y esta forma de expresión estaba ligada estrechamente al culto ${ }^{8}$. En cuanto a las danzas aparentemente religiosas, además de los términos nahuas de la división general ya mencionada, conocemos los nombres particulares de las actividades dancísticas típicas de las determinadas fiestas indígenas, como el nematlaxo, baile callado con flores cempoalxochitl de la veintena Ochpaniztli ${ }^{9}$, netecuitotilo de la veintena Izcalli, en el que participaban solamente los señores y los prinicipales ${ }^{10} \mathrm{o}$ toxcachocholoa, baile típico de la veintena Toxcatl $^{11}$.

Los misioneros españoles pronto se dieron cuenta de la importancia de los bailes en la vida religiosa de los indígenas ${ }^{12}$. Fray Pedro de Gante en la carta de 1558 dirigida

6 Para más información acerca de los bailes prehispánicos remitimos al lector a los siguientes estudios: M. Sten, Ponte a bailar, tú que reinas. Antropología de la danza prehispánica, México 1990; S. Martí, G. Prokosch Kurath, Dances of Anabuac. The Choreography and Music of Precortesian Dances, New York 1964 (Viking Fund Publications in Anthropology, 38); M. Danilović, 'El valor simbólico de las danzas femeninas en el caso de las fiestas Tecuilhuitontli, Huey Tecuilhuitl, Ochpaniztli y Tititl', Tesis de maestría (inédita), UNAM, Facultad de Filosofía y Letras, México 2009.

7 T. de Benavente Motolinía, Memoriales. Libro de oro (MS JGI 31), ed. N.J. Dyer, México 1996, p. 543 (Biblioteca Novohispana, 3).

8 S. Alberro, 'Bailes y mitotes coloniales como producto y factor sincrético' en A. Lupo, A. López Austin (ed.), La cultura plural. Reflexiones sobre diálogo y silencios en Mesoamérica. Homenaje a Italo Signorini, México 1998, p. 121.

9 Bernardino de Sahagún, The Florentine Codex. General History of the Things of New Spain, trad. Ch.E. Dibble, A.J.O. Anderson, pt. 3. Book 2: The Ceremonies, Santa Fe 1981, p. 118-124 (Monographs of the School of American Research and The Museum of New Mexico, 14).

10 Idem, Historia general de las cosas de la Nueva España, ed. J.C. Temprano, Vol. 1, Madrid 2001, p. 241 (Crónicas de América (Dastin), 23).

11 Ibid., p. 162.

12 M. Ramos Smith, La danza en México durante la época colonial, México 1990, p. 13-21 (Noventa). 
al rey Felipe II notó que toda su adoración dellos a sus dioses era cantar y bailar delante dellos ${ }^{13}$. Algunos de los frailes como fray Bernardino de Sahagún o fray Diego Durán estaban conscientes de lo ambiguo de estas prácticas y mostraban sus dudas acerca de si debería permitirse su perduración al servicio del cristianismo. Francisco Cervantes de Salazar mantenía que sería mejor desnudarlos del todo de las reliquias y rastros de su gentilidad, porque ha acontecido, según dicen religiosos de mucho crédicto, estar haciendo el baile alrededor de una cruz y tener debajo de ella soterrados los ídolos ${ }^{14}$. A pesar de ello, la mayoría de los religiosos actuaba de acuerdo con la opinión del jesuita José de Acosta, quien afirmaba que es digno de admitir que lo que pudiere dejar a los indios de sus costumbres y usos (no habiendo mezcla de sus errores antiguos), es bien dejallo y conforme al consejo de San Gregorio Papa, procurando que sus fiestas y regocijos se encaminen al honor de Dios y de los santos cuyas fiestas celebran ${ }^{15}$. De esta manera los bailes indígenas estaban presentes en las importantes ceremonias religiosas y civiles del siglo XVI: la pascua de resurrección ${ }^{16}$, la instauración del Santísimo Sacramento en la iglesia de San Francisco en $1525^{17}$, la jura de Felipe II en 1557 o la entrega por Alonso de Villaseca de una estatua de plata de la Virgen en Tepeyacac en $1566^{18}$, para enumerar solo algunas de las ocasiones. Durante su recorrido por las provincias y poblaciones de Nueva España al fray Alonso Ponce en casi todas las localidades los indígenas le recibían bailando y danzando a su modo ${ }^{19}$. Los bailes de los naturales se incorporaban también a las representaciones del teatro evangelizador, como en el caso del Auto de los Reyes Magos de Tlaxomulco en $1578^{20}$.

Los frailes españoles se servían también de otro recurso más en su tarea evangelizadora que se basaba en la tradición indígena. Fray Pedro de Gante refiere: [...] compuse metros muy solemnes sobre la Ley de Dios y de la fe, y cómo Dios se hizo hombre por salvar el linaje humano, y cómo nació de la Virgen María, quedando ella puraé sin mácula; y esto dos meses poco más o menos antes de la Natividad de Cristo, y díles libreas para pintar en sus mantas para bailar con ellas, porque ansi se usaba entre ellos [... ${ }^{21}$.

Esta práctica fue una técnica bastante común de trasmitir a los indígenas los preceptos de la doctrina cristina. Motolinía menciona que por motivo de las distintas fiestas los nahuas bailan y dicen cantares en su lengua, de las fiestas que celebran, que los frailes

13 J. García Icazbalceta (ed.), Códice franciscano, siglo XVI. Informe de la provincia del Santo Evangelio al Visitador Lic. Juan de Ovando. Informe de la provincia de Guadalajara al mismo. Cartas de religiosos, 1533-1569, México 1941, p. 206 (Nueva coleccion de documentos para la historia de Mexico. Seccion de historia, 4).

14 F. Cervantes de Salazar, Crónica de la Nueva España, Vol. 1, Barcelona 2008, p. 63 (Diferencias).

15 J. de Acosta, Historia natural y moral de las Indias, ed. E. O'Gorman, México 1962, p. 318 (Biblioteca Americana (Fondo de Cultura Económica), 38).

16 T. de Benavente Motolinía, Memoriales..., p. 241.

17 G. de Mendieta, Historia eclesiástica indiana, Vol. 1, México 2002, p. 369 (Cien de México).

18 Actas de Cabildo de México citado in S. Alberro, 'Bailes y mitotes...', p. 125.

19 Antonio de Ciudad Real, Tratado..., Vol. 1, p. 36, 73, 90, 104 y otras.

20 Ibid., Vol. 2, p. 100-103.

21 J.García Icazbalceta (ed.), Códice franciscano..., p. 206-207. 
se los han traducido ${ }^{22}$. Los mismos frailes componían nuevos tipos de cantos para responder a los gustos de los indígenas y a sus propias necesidades y así, supuestamente, garantizar su éxito en la acción evangelizadora. A fray Bernardino de Sahagún se le atribuye la autoría de la Psalmodia Christana ${ }^{23}$. Los Anales de Juan Bautista indican a fray Pedro de Gante como el inventor de un nuevo "género" de cantos, el pipilcuicatl, interpretado durante la fiesta de San Francisco en Tlatelolco en $1567^{24}$. No obstante, al lado de la creación original de los frailes florecían los cantares prehispánicos sometidos a los "reajustes" imprescindibles. Como señala Arthur J.O. Anderson, el análisis de los productos de esta adaptación de los textos por parte de los religiosos deja ver que muchas veces su intervención en el texto se reducía a sustituir los nombres de las divinidades prehispánicas por el término español "Dios", como en el caso de un evidente canto a un dios guerrero (¿Huitzilopochtli?) suplido por el Dios cristiano ${ }^{25}$ :

- zan topan moyahuatopan tzerzelihui a nezcalizxochitl yahuiltiloca in icelteotl Dios tetatzin ycahcahuanca y chimallin ...

ya sobre nosotros se difunden, sobre nosotros lloviznan las flores del combate, las que dan placer al Dios único, al Dios Padre. Hacen estruendo las rodelas... ${ }^{26}$

Por supuesto la conservación y la práctica de los bailes y cantos de antes de la conquista, arraigados en el culto antiguo, podía llevar a las situaciones como esta a la que llamó la atención Francisco Cervantes de Salazar: se les hapermitido, por darles contento, este baile, con que, como cantaban alabanzas del demonio, canten alabanzas de Dios, que sólo meresce ser alabado; pero ellos son tan inclinados a su antigua idolatría que si no hay quien entienda muy bien la lengua, entre las sacras oraciones que cantan mesclan cantares de su gentilidad, y para cubrir mejor su dañada obra, comienzan y acaban con palabras de Dios, interponiendo las demás gentílicas, abaxando la voz para no ser entendidos y levantándola en los principios y fines, cuando dicen "Dios".

Quizás por ello ya en 1539 la Junta ecclesiástica decidió [...] que se quitasen de las iglesias los areitos [...] asi por ser cosa de curiosidad seglar [...] como por usarse tanto los areitos en los ritos gentílicos, que hacian y solian hacer estos naturales en tiempo de su infidelidad. De acuerdo con estas regulaciones, los bailes podían realizarse [...] después de

22 T. de Benavente Motolinía, Memoriales..., p. 235.

23 Bernardino de Sahagún, Psalmodia christiana y Sermonario de los sanctos del año, en lengua mexicana, ed. J.L. Suárez Roca, León 1999.

24 L. Reyes García (ed.), Anales de Juan Bautista ¿Cómo te confundes? ¿Acaso no somos conquistados?, México 2001, p. 165 (Historias (Centro de Investigaciones y Estudios Superiores en Antropología Social)). En la misma fuente se mencionan también otros tipos de cantos aparentemente relacionados temáticamente con la doctrina cristiana, como por ejemplo el papalocuicatl, p. 149, interpretado durante la fiesta de San Juan en el año 1566 en México-Tenochtitlan, y el tequiquixtilizcuicatl que, de acuerdo con el comentario de Reyes García, tenía que ver con la expulsión de los primeros hombres del Paraíso, p. 197.

25 A.J.O. Anderson, 'La salmodia de Sahagún', Estudios de Cultura Náhuatl, Núm. 20 (1990), p. 24.

26 A.M. Garibay K., Cantares mexicanos. Manuscrito de la Biblioteca Nacional de México, Vol. 2, México 1968, p. 11 (Fuentes Indigenas de la Cultura Nábuatl, 6), citado in A. J. O. Anderson, 'La salmodia..., p. 24. El subrayado es nuestro.

27 F. Cervantes de Salazar, Crónica..., Vol. 1, p. 63. 
las horas de comer hasta horas de visperas, siendo vistos y examinados primero los cantares que hubieran de cantar, por quien entienda y sepa la lengua [...] de manera que todo les ayude a ser buenos cristianos $^{28}$.

\section{TRUHANES Y ACRÓBATAS: ¿EL FOLCLORE ESPAÑOL?}

En muchos de los espectáculos coloniales podemos encontrar las figuras que parecen sacadas del medioevo europeo. Durante la representación de La conquista de Rodas en México en 1539, que conmemoraba la Tregua de Nizas, habia trubanes y decidores que decian en loor de Cortés y del virrey cosas muy de reir ${ }^{29}$. Cuando en Santa Fe en 1586, fray Alonso Ponce presenció una escena que recuerda un motivo de memento mori burlesco: delante de él [...] salió un indio en figura de la muerte, y con él otro en figura y traje de negro diciendo muchas gracias, asi a los frailes como a los indios y a la mesma muerte, con la cual fue un rato jugando al quince con unos naipes viejos, y cuando no jugaba tañia una guitarra y decía donaires, hablando como negro bozal ${ }^{30}$.

Durante su recorrido el mismo padre comisario podía disfrutar de un truco "mágico" cuando un indio, al son de la guitarra tocada por su compañero, encontraba los objetos escondidos por el público ${ }^{31}$.

El atribuir este repertorio de las figuras aparentemente carnavalescas a la herencia medieval europea puede ser, no obstante, un poco precipitado y problemático, ya que los espectáculos de tipo juglaresco tienen también sus patrones en la época prehispánica. Los tlatoque o gobernantes indígenas se rodeaban de los personajes cuyo aspecto y formas de actuar traían a la memoria de los cronistas los ejemplos de Europa, por lo cual estos no vacilaban en denominarlos con los términos propios de su cultura. Así, en el palacio de Motecuhzoma tenemos a los "indios corcovados", "chocarreros", "truhanes" y "graciosos" 32 ; los mismos protagonistas participaron en la ceremonia de armarse caballeros, descrita por Diego Muñoz Camargo ${ }^{33}$.

En el mundo de los espectáculos indígenas fray Diego Durán menciona "un baile y canto de los truhanes": También habia otro baile tan agudillo y deshonesto que casi tira al baile de esta zarabanda que nuestros naturales usan con tantos meneos y visages $y$ deshonestas monerías que facilemente se verá ser baile de mugeres deshonestas y hombres livianos. Llamábanle cuecuechcuicatl que quiere decir baile cosquilloso o de comezón. En algunos pueblos le he visto bailar lo cual permiten los religiosos por recrearse:

28 Citado in B. Aracil Varón, El teatro evangelizador. Sociedad, cultura e ideología en la Nueva España del siglo XVI, Roma 1999, p. 530-531 (Studi di letteratura ispano-americana. Biblioteca della ricerca). B. Díaz del Castillo, Historia verdadera de la conquista de la Nueva España, México 2008, p. 641.

30 Antonio de Ciudad Real, Tratado..., Vol. 2, p. 78.

31 Ibid., p. 87.

32 F. Cervantes de Salazar, Crónica..., Vol. 1, p. 351; B. Díaz del Castillo, Historia verdadera..., p. 195.

33 D. Muñoz Camargo, Descripción de la ciudad y provincia de Tlaxcala, ed. R. Acuña, San Luis Potosí 2000, p. 151 (Biblioteca tlaxcalteca). 
ello no es muy acertado por ser tan deshonesto. En el cual se introducen indios vestidos como mujeres ${ }^{34}$.

Talvez a esta descripción corresponde un género de cantos prehispánicos de carácter leve xochicuicatl cuecuechtli, llamados por el padre Garibay “poemas de travesuras”, en los que los autores o protagonistas se autodefinen como burladores ${ }^{35}$.

Por otro lado, un fragmento de los Primeros Memoriales de Sahagún, traducido y publicado por el padre Garibay en "Paralipómenos de Sahagún”36, nos ofrecen todo un repertorio de artistas indígenas que hoy calificaríamos como prestidigitadores: el teuquiquixti, "el que hace saltar a los dioses", que era un tipo de titiritero; el motetequi o "destrozador", que fingía desmembrarse a sí mismo ante el público para luego recuperar su forma anterior, o el amamalacacho, es decir, "el que hace dar vueltas al agua". Entre los performers indígenas tampoco faltaron los acróbatas o saltimbanquís. En la Historia... de Durán encontramos una descripción del espectáculo del palo volador, de lo alto del cual cuatro indígenas, muchas veces disfrazados de pájaros, bajaban por unas cuerdas, dando vueltas ${ }^{37}$. El mismo cronista nos habla también del "baile de un palo rollizo" ${ }^{38}$ que consistía en que un indígena echado de espaldas en el suelo; levanta los pies, $y$ con las plantas y dedos trae un palo rollizo del grueso de una pierna, y, sin caérsele, lo arroja en el aire y lo torna a recibir, dando tantas vueltas con él en tantas maneras, unas veces con el un pie y otras con ambos, que es cosa bien de ver ${ }^{39}$.

Esta acrobacía fue presentada delante de la corte de Carlos I por un grupo de los nativos del México Central, llevados a España en 1528 por Hernán Cortés. La “compañía artística" de los aztecas después hizo un recorrido muy exitoso por todo el país; sus espectáculos fueron rendidos gráficamente por un alemán Christoph Weiditz ${ }^{40}$.

\section{LAS BATALLAS FINGIDAS O MOROS Y CRISTIANOS EN NUEVA ESPAÑA}

Los espectáculos de moros y cristianos en México en la época novohispana son tema de numerosos estudios completos, entre los cuales podemos mencionar el de Arturo War$\operatorname{man}^{41}$ o de Max Harris ${ }^{42}$. Por cuestiones del espacio en este apartado solo señalaremos

34 D. Durán, Historia de las Indias de la Nueva España e Islas de la Tierra Firme, Vol. 1, México 2006, p. 193.

35 A.M. Garibay K., 'Poema de travesuras', Tlalocan, Vol. 3, Núm. 2 (1952), p. 142-167.

36 Idem, 'Paralipómenos de Sahagún', Tlalocan, Vol. 2, Núm. 3 (1947), p. 235-254.

37 D. Durán, Historia..., Vol. 1, p. 194.

38 Ibid.

39 F. Cervantes de Salazar, Crónica..., Vol. 1, p. 63.

40 M. Harris, Aztecs, Moors and Christians. Festivals of Reconquest in Mexico and Spain, Austin 2000, p. 176. Agradecemos a Alex Kerner el indicarnos los dibujos de este gráfico alemán.

41 A. Warman Gryj, La danza de moros y cristianos, México 1972 (SepSetentas, 46).

42 M. Harris, Aztecs... 
cómo en la representación de una aprente raigambre europea se conjugan los elementos existentes en el mundo indígena y los llevados a México por los españoles.

La introducción de este tópico escénico en Nueva España se dataría, a base del testimonio de Bernal Díaz del Castillo, a finales del 1524 o a principios del 1525, cuando Cortés, yendo hacia la provincia de Hibueras, paró en Coatzacoalco ${ }^{43}$. Más tarde la danza guerrera, a menudo "adaptada" a las condiciones locales (sustitución de los trajes turcos por los chichimecas), se hizo muy popular en otras partes del virreinato, así que fray Alonso Ponce pudo presenciarla con mucha frecuencia y en las variantes más o menos elaboradas ${ }^{44}$. Pero en el siglo XVI dos eran las representaciones que por la escala en que se realizaron excedieron a todas las demás. Se trata de la escenificación de La conquista de Rodas en la Ciudad de México en la temporada de las Pascuas de Resurrección ${ }^{45}$ y La conquista de Jerusalén llevada a cabo en Tlaxcala durante la fiesta de Corpus Christi del mismo año ${ }^{46}$.

Las escaramuzas fingidas o ritualizadas contaban, no obstante, también con una presencia bien marcada en los rituales prehispánicos de los nahuas. Las peleas dramatizadas tenían lugar en las veintenas de Tlacaxipehualiztli ${ }^{47}$, Ochpaniztli ${ }^{48}$, Tititl ${ }^{49}$, Panquetzaliztli $i^{50}$, Huey Tozoztli ${ }^{51}$. Según las relaciones de las que disponemos acerca de las luchas fingidas antes de la llegada de los españoles y las coloniales, resulta que muchas veces, además de un tipo de guión según el cual se desarrollaban (y con el desenlace conocido

43 A. Warman Gryj, La danza.., p. 74.

Antonio de Ciudad Real, Tratado..., Vol. 1-2. Véase también M. Harris, Aztecs..., p. 153-160.

45 B. Díaz del Castillo, Historia verdadera..., p. 637-639. Véase también P. Lopes Don, 'Carnivals, Triumphs, and Rain Gods in the New World: A Civic Festival in the City of México-Tenochtitlán in 1539', Colonial Latin American Review, Vol. 6, Núm. 1 (1997), p. 17-40, en <http://dx.doi. org/10.1080/10609169708569906>.

46 T. de Benavente Motolinía, Historia de los indios de la Nueva España, ed. C. Esteva Fabregat, Madrid 2001, p. 138-147 (Crónicas de América, 17). Acerca de este tema véanse también B. Aracil Varón, 'Del texto literario a la representación popular sobre la conquista: La destrucción de Jerusalén', Anales de Literatura Española, Núm. 13 (1999), pp. 29-40; V. Díaz Balsera, 'Celebrating the Arrival of a New Sun. The Tlaxcalans Conquer Jerusalem in 1539', Estudios de Cultura Nábuatl, Núm. 39 (2009), p. 311-330.

47 J. de Torquemada, Monarquí..., Vol. 2, p. 253; Bernardino de Sahagún, Historia..., Vol. 1, p. 79; idem, The Florentine Codex..., pt. 3. Book 2, p. 50.

48 Bernardino de Sahagún, The Florentine Codex..., pt. 3. Book 2, pp. 19, 120-121; idem, Historia..., Vol. 1, p. 194; D. Durán, Historia..., Vol. 1, p. 146; J. de Torquemada, Monarquia..., Vol. 2, p. 276; J. de la Serna, 'Manual de ministros de indios para el conocimiento de sus idolatrías, y extirpación de ellas' en F. del Paso y Troncoso (ed.), Tratado de las idolatrias, supersticiones, dioses, ritos, hechicerias y otras costumbres gentilicas de las razas aborigenes de Mexico, Vol. 1, México 1953, p. 130.

49 Bernardino de Sahagún, The Florentine Codex..., pt. 3. Book 2, p. 157-158; idem, Historia..., Vol. 1, p. 136, 236; idem, Primeros Memoriales, trad. T.D. Sullivan, H.B. Nicholson, Norman 1997, p. 66 (Civilization of the American Indian Series, v. 200, pt. 2); D. Durán, Historia..., Vol. 1, p. 289; J. de Torquemada, Monarquía..., Vol. 2, p. 285.

50 Bernardino de Sahagún, The Florentine Codex..., pt. 3. Book 2, p. 149; idem, Historia..., Vol. 1, p. 214; idem, Primeros..., p. 65.

51 Idem, The Florentine Codex..., pt. 3. Book 2,, p. 63; idem, Historia..., Vol. 1, p. 117; J. de Torquemada, Monarquia..., Vol. 2, p. 255. 
desde el inicio), el punto en común que tenías estos espectáculos era la utilización de las armas poco dañinas de origen vegetal como las pelotas de espadañas ${ }^{52}$. Entre los antecedentes indígenas de los moros y cristianos Harris enumera también las guerras floridas $(\text { xochiyaoyotl })^{53}$. De hecho, la escenificación de las batallas indígenas en Europa tuvo lugar en Sevilla en 1522, que es dos años antes que el espectáculo de origen medieval en América ${ }^{54}$.

Como podemos ver, incluso un tipo de representación tan arraigado en la Península Ibérica y trasplantado a Nueva España, que desde el punto de vista de los españoles seguía siendo el mismo a pesar de algunas adaptaciones locales a nivel del vestuario u objetos de utilería, no necesariamente lo era desde la perspectiva indígena. Igual los nahuas podían reconocer en el esquema del espectáculo los patrones que existían en su cultura en los tiempos prehispánicos y tratarlos como suyos, solo que modificados por algunos componentes extranjeros.

\section{EL TEATRO EVANGELIZADOR}

No existe una opinión unívoca sobre el grado de aportación indígena al teatro religioso introducido por los franciscanos en la Nueva España. Según Othon Arróniz, los diferentes aspectos de "lo teatral" no contribuyeron de ninguna manera a la forma dramática implementada por los religiosos españoles y los franciscanos creadores del teatro de evangelización parten, por así decirlo, de la nada ${ }^{55}$. O, más bien, parten del exemplum de la tradición didáctica medieval ${ }^{56}$. Al otro extremo se sitúan las afirmaciones como la de Maria Sten de que si bien nada podian aportar [los indígenas] en materia de texto, [...] plasmaban su visión del espectáculo a través de otros elementos: la música, el baile, el vestuario, y todos los elementos que hoy llamaríamos audiovisuales ${ }^{57}$. La mayoría de los

52 Bernardino de Sahagún, The Florentine Codex..., pt. 3. Book 2, p. 19; T. de Benavente Motolinía, Historia..., p. 145. Es importante subrayar al respecto que, a diferencia de los moros y cristianos, un espectáculo secular cuyo objetivo era más que nada la diversión, en el caso de las luchas prehispánicas mencionadas se trata de unos enfrentamientos ritualizados, en los que los atavíos, los movimientos corporales y las armas utilizadas están cargados de simbolismo. Así, por ejemplo, durante la batalla llamada cacali, relacionada con la veintena Panquetzaliztli, los grupos contrincantes de alumnos de la escuela calmecac (futuros sacerodtes) y los del telpochcalli (futuros guerreros) cuando se tiraban las cañas, estas eran "atadas unas con otras de tres en tres o de cuatro en cuatro". In Bernardino de Sahagún, The Florentine Codex..., pt. 3. Book 2, p. 149; idem, Historia..., Vol. 1, p. 214. Agradecemos a Katarzyna Mikulska el llamar nuestra atención sobre este detalle.

M. Harris, Aztecs..., p. 67-104.

Ibid., p. 19.

O. Arróniz, Teatro de evangelización en Nueva España, México 1979, p. 11 (Letras del XVI al XVIII).

M.K. Schuessler, 'Precursores iconográficos y arquitectónicos del teatro misionero novohispano', Destiempos. Dossier: Virreinatos, Año 3, Núm. 14 (2008), p. 97, en <http://www.destiempos.com/n14/ schuessler.pdf $>$.

57 M. Sten, 'Sincretismo del teatro evangelizante' en eadem (coord.), El teatro franciscano en la Nueva España. Fuentes y ensayos para el estudio del teatro de evangelización en el siglo XVI, México 2000, p. 142. 
investigadores están, no obstante, de acuerdo de que los antecedentes del teatro evangelizador novohispano se hallan tanto en la cultura medieval europea como en las representaciones prehispánicas de los indígenas ${ }^{58}$, aunque la aportación de los nativos muchas veces se considera escasa y reducida al escenario, espacio y vestuario ${ }^{59}$ (vide infra).

$\mathrm{Al}$ señalar la presencia nahua en los dramas coloniales James Lockhart indica que a veces los mismos autores franciscanos admitían haber recurrido a la ayuda de los indígenas a la hora de escribir las piezas teatrales, como es el caso de fray Juan Bautista y su colaboración con uno de los informantes de Sahagún, Agustín de la Fuente ${ }^{60}$. La participación de los nativos es notable a nivel filológico y se deja ver en los textos, entre otros, en la ortografía de los préstamos del español, hipercorrecta y sometida a las sustituciones comunes en el náhuatl de los siglos XVI y XVII ${ }^{61}$ o en la retórica nahua plasmada en los diálogos ${ }^{62}$. Como ejemplos Lockhart cita las palabras con las que Herodes da la bienvenida al mensajero de los Reyes Magos ${ }^{63}$ o el discurso de Abraham dirigido a su hijo Isaac que imita el estilo de las prehispánicas huehuetlatolli o "pláticas de los viejos" ${ }^{6}$. En el Auto de los Reyes Magos Gaspar saluda al Niño Jesús diciendo:

- Gaspar = Tlacatlen toteCuioyen tlaçochalChibuitlen quetzalen teoxihuitlen maquistlen ca ye nican Otibualmohuetzititzino in nican Omitzhualmotlalilitzino in motlaçotatzin D.' tloqyen nabuaqueyen ipaltzinco nemohualonien

CASPER: ¡Oh Señor!, ¡oh Nuestro Señor!, ¡oh jade precioso!, ¡oh plumas de quetzal!, joh turquesa fina!, joh pulsera! Te has bajado aquí. Te ha asentado aquí tu precioso padre, Dios, ¡oh Señor del Ceca y del Junto!, joh Señor por quien vivimos! ${ }^{65}$

En las obras dramáticas novohispanas encontramos también a los personajes con características indígenas, colocados dentro del contexto social prehispánico: incluso el patriarca bíblico, Abraham, aparece como un tlatoani de su altepetl, mientras que Agar e Ismael pertenecen al grupo particular de sirvientes, los tetlan nenque ${ }^{66}$. Por último, de vez en cuando de la lectura de estas piezas teatrales surgen unas "irregularidades doc-

58 L.M. Burkhart, Holy Wednesday. A Nahua Drama from Early Colonial Mexico, Philadelphia 1996, p. 43 (New Cultural Studies); A. Partida (ed.), Teatro de evangelización en nábuatl, Vol. 2, México 1992, p. 26 (Teatro mexicano); S. Poole, 'The Virgin of Guadalupe in Two Nahuatl Dramas' en B.D. Sell, L.M. Burkhart (ed.), Nahuatl Theater, Vol. 2: Our Lady of Guadalupe, Norman 2006, p. 4; I.H. Posada Cano, 'El teatro de evangelización en Mesoamérica: Los códigos de sincretismo cultural', A-mérika, Vol. 2, Núm. 3 (2009), p. 1-16.

59 M.K. Schuessler, 'Precursores..., p. 97; B. Aracil Varón, El teatro..., p. 288.

60 J. Lockhart, Los nabuas después de la conquista. Historia social y cultural de la población indígena del México central, siglos XVI-XVIII, trad. R. Reyes Mazzoni, México 1999, p. 570 (Sección de Obras de Historia).

Ibid.

62 Ibid, p. 576.

63 Ibid. Véase también 'The Three Kings' en B.D. Sell, L.M. Burkhart (ed.), Nabuatl Theater, Vol. 1: Death and Life in Colonial Nahua Mexico, Norman 2004, p. 122-123.

64 J. Lockhart, Los nahuas..., p. 575. Véase también 'The Sacrifice of Isaac' en B.D. Sell, L.M. Burkhart (ed.), Nahuatl Theater, Vol. 1 p. 150-151.

65 'The Three Kings', p. 136-137. La traducción del náhuatl al español es de Agnieszka Brylak.

66 Ibid., p. 577. 
trinales ocasionales", que aparentemente pasaron desapercibidas por los frailes, como la identificación del Dios padre con la Santísima Trinidad, sin hacer caso a Jesucristo ${ }^{67}$.

\section{ESCENARIO, OBJETOS DE UTILERÍA Y VESTUARIO}

Entre los aspectos en los que se nota la aportación indígena a los espectáculos coloniales Beatriz Aracil Varón enumera el decorado natural, los cuadros de caza, el vestuario indígena (sobre todo los trajes de guerreros y los disfraces de animales), los cantos y la capacidad histriónica $^{68}$. Veamos ahora algunos ejemplos.

Durante muchas de las fiestas religiosas novohispanas y los espectáculos que las acompañaban se recreaba el paisaje natural. Según el testimonio de Bernal Díaz del Castillo, durante las festividades para conmemorar la firma de paz en Aguas Muertas por los reyes de España y de Francia, en la plaza mayor de México se construyó un bosque con tanta diversidad de árboles, tan al natural como si allí hubiera nacido. Habia en medio unos árboles como que estaban caídos de viejos y podridos, y otros llenos de moho, con unas yerbecitas que parece que nacian de ellos ${ }^{69}$. En él habitaba gran variedad de pájaros y animales, lo que permitió llevar a cabo la cacería. ${ }^{70}$ En un espacio forestal lleno de aves y con las montañas artificiales también se desarrollaban las ceremonias de Corpus Christi en Tlaxcalla en 1538, en las que no faltaron unos cazadores disfrazados ${ }^{71}$.

Los peñones contrahechos en la naturaleza recreada sirvieron de escenario de varios autos sacramentales. Por motivo de Corpus Christi en 1538 en Tlaxcala se realizaron cuatro espectáculos del teatro edificante: En la primera destas montañas estaba la representación de Adán y Eva y la serpiente que los engañó. En la segunda, la tentación del Senor. En la tercera, San Jerónimo, y en la cuarta, nuestro padre San Francisco ${ }^{72}$. Unas semanas antes, el miércoles de la octava de Pascuas, los tlaxcaltecas pudieron ver La caída de nuestros primeros padres representada en un espacio paradísiaco con montes, ríos y una exuberancia del mundo vegetal y animal, todo esto fabricado por los indígenas con "gracia singular"73. El paisaje artificial con peñones también sirvió de escena en Tlaxcala durante el Corpus Christi de 1539 cuando se representaron tres piezas tetarales: La tentación de Jesucristo, La predicación de San Francisco a las aves y El sacrificio de Isaac ${ }^{74}$.

\footnotetext{
67 Ibid., p. 570.

68 B. Aracil Varón, El teatro..., p. 288-290.

69 B. Díaz del Castillo, Historia..., p. 638.

70 Ibid. Vésae también H. Hernán Ramírez, Fiesta, espectáculo y teatralidad en el México de los conquistadores, Madrid-Frankfurt am Main-México 2009, p. 87 (Textos y Estudios Coloniales y de la Independencia, 19).

71 T. de Benavente Motolinía, Historia..., p. 132.

72 B. de las Casas, Apologética historia sumaria, ed. E. O’Gorman, Vol. 1, México 1967, p. 331 (Serie de Historiadores y Cronistas de Indias, 1).

73 T. de Benavente Motolinía, Historia..., p. 136.

74 Ibid., p. 147.
} 
La elaboración del paisaje que imitara la naturaleza tenía sus antecedentes en la realización de las fiestas indígenas en la época prehispánica. Durante las ceremonias en honor a Xochiquetzal [...] hacian una casa de rosas y hacian unos árboles a mano, muy llenos de flores olorosas, a donde hacian sentra a la diosa Xochiquetzal. Mientras bailaban, descendian unos muchachos, vestidos todos como pájaros, y otros, como mariposas, muy bien aderezados de plumas ricas, verdes y azules y coloradas y amarillas. Subianse por estos árboles y andaban de rama en rama chupando el rocio de aquellas flores ${ }^{75}$.

La preparación de las imágenes de los montes (en náhuatl tepictoton) formaba parte del culto mesoamericano a las montañas. Así, los ritos principales de la veintena Tepeilbuitl consistían en hacer de la masa de amaranto, llamada tzoalli, unas figuras de montes reales, proveídas de órganos sensoriales, que se colocaban de tal manera que reflejaran su ubicación en el espacio geográfico del México Central ${ }^{76}$.

Otro ejemplo relevante que tiene que ver con la construcción del escenario por parte de los indígenas está relacionado con la puesta en escena de La conquista de Jerusalén en Tlaxcala en 1539 durante el Corpus Christi. Entonces se hicieron cinco torres; la una de homenaje en medio, mayor que las otras, y las cuatro a los cuatro cantos. ${ }^{77}$ Esta organización del espacio tiene su correspondiente en la cosmovisión indígena, con los cuatro árboles cósmicos dispuestos en los cuatro rumbos y el quinto en el centro, que forman un conjunto espacio-temporal completo ${ }^{78}$.

Si nos fijamos en el vestuario utilizado en las fiestas y representaciones coloniales, parece que los indígenas gozaban de bastante libertad a la hora de elegir los trajes. Así, al realizar sus bailes normalmente los nativos salían vestidos todos según lo solian hacer ${ }^{79}$. Otras veces aprovechaban la ocasión para lucir sus atavíos de guerra antiguos, como en el caso del desfile de los guerreros águilas y jaguares delante del arzobispo Montúfar, rendidos en el Códice Tlatelolco ${ }^{80}$. La clara aportación indígena en esta materia se nota también en la puesta en escena de La conquista de Jerusalén en Tlaxcala (1539), en la que solo ellos salían como actores. Según la descripción de Motolinía, los representantes del ejército europeo, formado tanto por los soldados de distintas regiones de España como por los italianos y alemanes, a nivel del vestuario parecen todos iguales o, más bien, todos españoles, mientras que los miembros de varios grupos indígenas que constituyen otra parte del ejército, se dejan distinguir muy bien por la variedad de trajes ${ }^{81}$.

Los disfraces de animales son otro elemento presente en los espectáculos novohispanos que Beatriz Aracil Varón denota como propio de sus dramatizaciones ${ }^{82}$. Los hombres

75 D. Durán, Historia..., Vol. 1, p. 192.

76 Ibid., Vol. 1, p. 165; Bernardino de Sahagún, Historia..., Vol. 1, p. 202.

77 T. de Benavente Motolinía, Historia..., p. 139.

78 Véase la lámina 1 del F. Anders et al. (ed.), Códice Fejervary-Mayer, Graz-México 1994 (Códices Mexicanos, 7).

79 Antonio de Ciudad Real, Tratado..., Vol. 1, p. 13, 103; Vol. 2, p. 19 y otras.

$80 \quad$ P. Valle P. (ed.), Códice de Tlatelolco, México-Puebla 1994 (Códices Mesoamericanos, 1).

81 T. de Benavente Motolinía, Historia..., p. 139-140.

82

B. Aracil Varón, El teatro..., p. 276. 
en trajes zoómorfos aparecen a menudo en las fiestas prehispánicas: de ardilla y murciérlago en la veintena Teotleco ${ }^{83}$, de coyotes en la veintena Tlacaxipehualiztli ${ }^{84}$ y Ochpanizt$l^{85}$ de varios tipos de pájaros o insectos durante la fiesta Atamalcualiztli ${ }^{86}$ o los rituales para Xochiquetzal (vide supra), para dar algunos ejemplos. Los personajes con un tipo de atavío parecido no faltan en las representaciones coloniales del teatro evangelizador. Así, durante el espectáculo de La caída de nuestros primeros padres (Tlaxcala 1539) un muchacho vestido como león [...] estaba desgrrando y comiendo un venado que tenía muerto ${ }^{87}$; en el mismo escenario paradísiaco Adán y Eva jugaban con otros animales bien contrahechos, metidos dentro unos muchachos ${ }^{88}$. Según Fernando Horcasitas, también al escenificarse la Predicación de San Francisco a las aves en el mismo año y lugar, con mucha probabilidad los volátiles que acompañaban al santo cristiano eran los pájaros bumanos ${ }^{89}$.

El último elemento del aporte indígena en la realización de los espectáculos novohispanos que perduraron desde los tiempos prehispánicos y que vamos a considerar son los objetos de utilería y el uso de las máscaras. Antes de la llegada de los españoles los nahuas empleaban en abundancia flores y plumas preciosas para adornar el espacio sagrado en el que transcurrían sus ceremonias religiosas. Con los mismos objetos en las manos, a veces sustituidos por mazorcas de maíz ${ }^{90}$, figuras de la mas $t z o a l l i^{91}$ o comida ${ }^{92}$, los indígenas efectuaban sus bailes rituales. Del mismo modo las máscaras eran un elemente intrínseco de las ceremonias prehispánicas ${ }^{93}$. La continuidad de estas costumbres indígenas no fue interrumpida durante la colonia gracias al consentimiento de los misioneros españoles, quienes las aplicaron a la ceremonialidad cristiana, sobre todo en la primera etapa de la evangelización, ya que a cargo de los nativos quedaba la preparación de la decoración durante las fiestas religiosas ${ }^{94}$. Al parecer la licencia de los frailes se

83 Bernardino de Sahagún, The Florentine Codex..., pt. 3. Book 2, p. 128; idem, Historia..., Vol. 1, p. 201.

M. Soler (ed.), Códice Borbónico. Manuscrito mexicano de la biblioteca del Palais Bourbon (Libro adivinatorio y ritual ilustrado) publicado en fascimil, México 1980, lám. 30 (América nuestra. América antigua, 21a).

86 Bernardino de Sahagún, Primeros..., p. 68; idem, The Florentine Codex..., pt. 3. Book 2, p. 177; idem, Historia..., Vol. 1, p. 246. Véase también M. Graúlich, 'Atamalcualiztli, fiesta azteca del nacimiento de Cinteotl-Venus', Estudios de Cultura Nábuatl, Vol. 32 (2001), p. 359-370.

87 T. de Benavente Motolinía, Historia..., p. 137. Fernando Horacitas dice acreca de esta escena de Tlaxcala que el león bien podia haber sido un muchacho disfrazado de jaguar en F. Horcasitas, Teatro nábuatl, Vol. 1: Épocas novohispana y moderna, México 2004, p. 686.

T. de Benavente Motolinía, Historia..., p. 136.

F. Horcasitas, Teatro..., Vol. 1, p. 689. Véase también B. Aracil Varón, El teatro..., p. 277.

Bernardino de Sahagún, The Florentine Codex..., pt. 3. Book 2, p. 104; idem, Historia..., Vol. 1, p. 183;

D. Durán, Historia..., Vol. 1, p. 265.

91 D. Durán, Historia..., Vol. 1, p. 121.

92 Bernardino de Sahagún, Historia..., Vol. 1, p. 152.

93 Bernardino de Sahagún, The Florentine Codex..., pt. 3. Book 2; Soler M. (ed.), Códice Borbónico..., láms. 23-37.

94 T. de Benavente Motolinía, Memoriales..., p. 232-233. 
debía a que trataban el apego de los indígenas a la ornamentación como muy superficial, mientras que las flores y plumas desempeñaban una función importante en la ritualidad prehispánica, ya que atraían el tonalli o la energía divina ${ }^{95}$. Tal vez este hecho explica una gran incidencia de las descripciones minuciosas del adorno usado en las festividades novohispanas, visible en los documentos muy concisos, como por ejemplo los anales, sobre todo si los autores eran indígenas o mestizos ${ }^{96}$. En la época colonial también estaban permitidos los bailes en máscaras y con cañas o flores en las manos ${ }^{97}$.

No obstante, a partir de los años 50 del siglo XVI empezaron a emprenderse varias regulaciones legislativas por parte de las autoridades civiles y eclesiásticas, que notaron el peligro de tales prácticas. En abril de 1550 los miembros de cabildo de Tlaxcala ordenaron que no se se quitaran las plumas de los objetos pertenecientes a la iglesia y que no se bailara con ellos bajo la multa de 80 pesos de minas ${ }^{98}$. El Primer Concilio Provincial de 1555 pidió que los indios [...] al tiempo que bailaren, no usen de insignias, ni máscaras antiguas, que pueden causar alguna sospech a, ni canten cantares de sus ritos e historias antiguas, sin que primero sean examinados los dichos cantares por religiosos o personas que entienden muy bien la lengua $a^{99}$, y el Tercer Concilio Provincial de México de 1585 prohibió que [...] tengan los indios sus acostumbrados bailes con coronas y otras insignias sospechosas ${ }^{100}$.

\section{CONSIDERACIONES FINALES}

El material esbozado en nuestro artículo demuestra cuán difícil es la separación de los elementos indígenas y los aportados del Viejo Mundo al considerar los espectáculos novohispanos del siglo XVI. Aunque se escuchan las voces como la de Hugo Hernán Ramírez de que estos sólo superficialmente se ven afectados por el entramado de aspectos encontrados en el continente en ese momento, como son las tradiciones indígenas ${ }^{101}$, nos parece casi imposible trazar la línea de demarcación entre las influencias que provienen del uno y del otro lado del Atlántico. ¿Qué veían los miembros de la polimorfa sociedad novohispana en la figura de un borracho que apareció en la escena durante la representación de la Predicación de San Francisco a las aves en Tlaxcala en $1539^{102}$ ?

95 Para más información acerca del tonalli y las demás entidades anímicas véase el estudio de A. López Austin, Cuerpo humano e ideología. Las concepciones de los antiguos nabuas, Vol. 1-2, México 1984 (Serie Antropológica, 39).

96 Agradecemos a Justyna Olko el llamar nuestra atención sobre este hecho.

97 A. de Ciudad Real, Tratado..., Vol. 1, p. 73; Vol. 2, p. 71, 123.

98 J. Lockhart, F. Berdan, A.J.O. Anderson, The Tlaxcalan Actas. A Compendium of the Records of the Cabildo de Tlaxcala (1545-1627), Salt Lake City 1986, p. 71.

99 Citado in B. Aracil Varón, El teatro..., p. 530.

100 Ibid.

101 H. Hernán Ramírez, Fiestas..., p. 15.

102 T. de Benavente Motolinía, Historia..., p. 149. 
¿A un variante de bobo de los entremeses españoles o a un personaje embriagado que en la época prehispánica bailaba aderezado de plumas preciosas ${ }^{103}$ ? ¿Cómo interpretar el acto de barrer que abre el camino a la procesión de Corpus Christi ${ }^{104}$ ? Probablemente estas preguntas tendrán que permanecer retóricas. El mundo de espectáculos coloniales es como un crisol en el que los patrones propios de los indígenas convergen con las manifestaciones aportadas por los europeos, por lo cual se prestan a una interpretación doble. Para mejor definir el estado de ser novohispano podemos llamarlo, usando las palabras de Patricia Lopes, un malentendido útil ${ }^{105}$ o recurrir al concepto de double-mistaken identity de James Lockhart ${ }^{106}$. Al parecer, lo sustancial a la hora de analizar estos fenómenos culturales sui generis no es buscar a fuerza las maneras de separar lo propio y lo ajeno en las representaciones coloniales sino intentar verlas también desde la óptica indígena para determinar si y cómo los coautores y actores principales en estos espectáculos notaban y sentían los efectos de la convergencia cultural y religiosa.

\section{BIBLIOGRAFÍA}

Alberro S., 'Bailes y mitotes coloniales como producto y factor sincrético' en A. Lupo, A. López Austin (ed.), La cultura plural. Reflexiones sobre diálogo y silencios en Mesoamérica. Homenaje a Italo Signorini, México 1998.

Anders F. et al. (ed.), Códice Fejervary-Mayer, Graz-México 1994 (Códices Mexicanos, 7). Anderson A.J.O., 'La salmodia de Sahagún', Estudios de Cultura Náhuatl, Núm. 20 (1990).

Antonio de Ciudad Real, Tratado curioso y docto de las grandezas de la Nueva España. Relación breve y verdadera de lagunas cosas de las muchas que sucedieron al padre fray Alonso Ponce en las provincias de la Nueva España siendo comisario general de aquellas partes, ed. J. García Quintana, V.M. Castillo Farreras, Vol. 1-2, México 1993.

Aracil Varón B., 'Del texto literario a la representación popular sobre la conquista: La destrucción de Jerusalén', Anales de Literatura Española, Núm. 13 (1999).

Aracil Varón B., El teatro evangelizador. Sociedad, cultura e ideología en la Nueva España del siglo

XVI, Roma 1999 (Studi di letteratura ispano-americana. Biblioteca della ricerca).

Arróniz O., Teatro de evangelización en Nueva España, México 1979 (Letras del XVI al XVIII). Benavente Motolinía T. de, Historia de los indios de la Nueva España, ed. C. Esteva Fabregat, Madrid 2001 (Crónicas de América, 17).

Benavente Motolinía T. de, Memoriales. Libro de oro (MS JGI 31), ed. N.J. Dyer, México 1996 (Biblioteca Novohispana, 3).

103 D. Durán, Historia..., Vol. 1, p. 194.

104 T. de Benavente Motolinía, Memoriales..., p. 233.

105 P. Lopes Don, 'Carnivals...'

106 J. Lockhart, 'Some Nahua Concepts in Postconquest Guise', History of European Ideas, Vol. 6, Núm. 4 (1985), p. 465-482, en <http://dx.doi.org/10.1016/0191-6599(85)90086-5>; idem, Of Things of the Indies. Essays Old and New in Early Latin American History, Stanford 1999, p. 99. 
Bernardino de Sahagún, The Florentine Codex. General History of the Things of New Spain, trad.

Ch.E. Dibble, A.J.O. Anderson, pt. 3. Book 2: The Ceremonies, Santa Fe 1981 (Monographs of the School of American Research and The Museum of New Mexico, 14).

Bernardino de Sahagún, Historia general de las cosas de la Nueva España, ed. J.C. Temprano, Vol.

1, Madrid 2001 (Crónicas de América (Dastin), 23).

Bernardino de Sahagún, Primeros Memoriales, trad. T.D. Sullivan, H.B. Nicholson, Norman 1997 (Civilization of the American Indian Series, v. 200, pt. 2).

Burkhart L.M., Holy Wednesday. A Nahua Drama from Early Colonial Mexico, Philadelphia 1996 (New Cultural Studies).

Casas B. de las, Apologética historia sumaria, ed. E. O’Gorman, Vol. 1, México 1967 (Serie de Historiadores y Cronistas de Indias, 1).

Cervantes de Salazar F., Crónica de la Nueva España, Vol. 1, Barcelona 2008 (Diferencias).

Curcio-Nagy L.A., The Great Festivals of Colonial Mexico City. Performing Power and Identity, Albuquerque 2004 (Diálogos).

Danilović M., 'El valor simbólico de las danzas femeninas en el caso de las fiestas Tecuilhuitontli, Huey Tecuilhuitl, Ochpaniztli y Tititl', Tesis de maestría (inédita), UNAM, Facultad de Filosofía y Letras, México 2009.

Díaz Balsera V., 'Celebrating the Arrival of a New Sun. The Tlaxcalans Conquer Jerusalem in 1539', Estudios de Cultura Nábuatl, Núm. 39 (2009).

Díaz del Castillo B., Historia verdadera de la conquista de la Nueva España, México 2008.

Durán D., Historia de las Indias de la Nueva España e Islas de la Tierra Firme, Vol. 1, México 2006.

García Icazbalceta J. (ed.), Códice franciscano, siglo XVI. Informe de la provincia del Santo Evangelio al Visitador Lic. Juan de Ovando. Informe de la provincia de Guadalajara al mismo. Cartas de religiosos, 1533-1569, México 1941 (Nueva coleccion de documentos para la historia de Mexico. Seccion de historia, 4).

Garibay K. A.M., Cantares mexicanos. Manuscrito de la Biblioteca Nacional de México, Vol. 2, México 1968 (Fuentes Indígenas de la Cultura Nábuatl, 6).

Garibay K. A.M., 'Paralipómenos de Sahagún', Tlalocan, Vol. 2, Núm. 3 (1947).

Garibay K. A.M., 'Poema de travesuras', Tlalocan, Vol. 3, Núm. 2 (1952).

Graúlich M., 'Atamalcualiztli, fiesta azteca del nacimiento de Cinteotl-Venus', Estudios de Cultura Nábuatl, Vol. 32 (2001).

Harris M., Aztecs, Moors and Christians. Festivals of Reconquest in Mexico and Spain, Austin 2000.

Hernán Ramírez H., Fiesta, espectáculo y teatralidad en el México de los conquistadores, MadridFrankfurt am Main-México 2009 (Textos y Estudios Coloniales y de la Independencia, 19).

Horcasitas F., Teatro nábuatl, Vol. 1: Épocas novohispana y moderna, México 2004.

Lockhart J., Los nabuas después de la conquista. Historia social y cultural de la población indígena del México central, siglos XVI-XVIII, trad. R. Reyes Mazzoni, México 1999 (Sección de Obras de Historia).

Lockhart J., Of Things of the Indies. Essays Old and New in Early Latin American History, Stanford 1999 ,

Lockhart J., 'Some Nahua Concepts in Postconquest Guise', History of European Ideas, Vol. 6, Núm. 4 (1985), en <http://dx.doi.org/10.1016/0191-6599(85)90086-5>. 
Lockhart J., Berdan F., Anderson A.J.O., The Tlaxcalan Actas. A Compendium of the Records of the Cabildo de Tlaxcala (1545-1627), Salt Lake City 1986.

Lopes Don P., 'Carnivals, Triumphs, and Rain Gods in the New World: A Civic Festival in the City of México-Tenochtitlán in 1539', Colonial Latin American Review, Vol. 6, Núm. 1 (1997), en <http://dx.doi.org/10.1080/10609169708569906>.

López Austin A., Cuerpo humano e ideología. Las concepciones de los antiguos nahuas, Vol. 1-2, México 1984 (Serie Antropológica, 39).

Martí S., Prokosch Kurath G., Dances of Anahuac. The Choreography and Music of Precortesian Dances, New York 1964 (Viking Fund Publications in Anthropology, 38).

Mendieta G. de, Historia eclesiástica indiana, Vol. 1, México 2002 (Cien de México).

Muñoz Camargo D., Descripción de la ciudad y provincia de Tlaxcala, ed. R. Acuña, San Luis Potosí 2000 (Biblioteca tlaxcalteca).

Partida A. (ed.), Teatro de evangelización en nábuatl, Vol. 2, México 1992 (Teatro mexicano).

Poole S., 'The Virgin of Guadalupe in Two Nahuatl Dramas' en B.D. Sell, L.M. Burkhart (ed.), Nabuatl Theater, Vol. 2: Our Lady of Guadalupe, Norman 2006.

Posada Cano I.H., 'El teatro de evangelización en Mesoamérica: Los códigos de sincretismo cultural', A-mérika, Vol. 2, Núm. 3 (2009).

Ramos Smith M., La danza en México durante la época colonial, México 1990 (Noventa).

Reyes García L. (ed.), Anales de Juan Bautista ¿Cómo te confundes? ¿Acaso no somos conquistados?, México 2001 (Historias (Centro de Investigaciones y Estudios Superiores en Antropología Social)).

Rivera O., 'Fiestas por los Austrias en la Ciudad de México, siglo XVI', Revista Destiempos. Dossier Virreinatos, Año 3, Núm. 14 (2008).

Schuessler M.K., 'Precursores iconográficos y arquitectónicos del teatro misionero novohispano', Destiempos. Dossier: Virreinatos, Año 3, Núm. 14 (2008), en <http://www.destiempos. com/n14/schuessler.pdf $>$.

Sell B.D., Burkhart L.M. (ed.), Nahuatl Theater, Vol. 1: Death and Life in Colonial Nahua Mexico, Norman 2004.

Serna J. de la, 'Manual de ministros de indios para el conocimiento de sus idolatrías, y extirpación de ellas' en F. del Paso y Troncoso (ed.), Tratado de las idolatrias, supersticiones, dioses, ritos, hechicerias y otras costumbres gentilicas de las razas aborigenes de Mexico, Vol. 1, México 1953.

Soler M. (ed.), Códice Borbónico. Manuscrito mexicano de la biblioteca del Palais Bourbon (Libro adivinatorio y ritual ilustrado) publicado en fascímil, México 1980, lám. 30 (América nuestra. América antigua, 21a).

Sten M., 'Sincretismo del teatro evangelizante' en eadem (coord.), El teatro franciscano en la Nueva España. Fuentes y ensayos para el estudio del teatro de evangelización en el siglo XVI, México 2000.

Sten M., Ponte a bailar, tú que reinas. Antropología de la danza prehispánica, México 1990.

Torquemada J. de, Monarquía indiana, introd. M. León Portilla, Vol. 2-3, México 1986 (Biblioteca Porrúa, 42, 43).

Valle P. P. (ed.), Códice de Tlatelolco, México-Puebla 1994 (Códices Mesoamericanos, 1).

Warman Gryj A., La danza de moros y cristianos, México 1972 (SepSetentas, 46). 
Dr Agnieszka BRYLAK works in the Institute of Iberian and Ibero-American Studies and at the Facutly of "Artes Liberales" at the University of Warsaw. She obtained a doctoral degree in the humanities in 2015 with the dissertation "Performances of the pre-Hispanic Nahuas: between anthropology and theatre". Her areas of interest are language and cultureof pre-Hispanic and colonial Nahuas and, particularly, worldview, religion, as well as festivals and performances in Mesoamerica and in New Spain. 